\title{
A Mata Atlântiea e sua conservação
}

Recebido: 15/11/2016. Aprovado: 30/11/2016.

\author{
Josiane Teresinha Cardoso*
}

Resumo: A Mata Atlântica é o terceiro maior bioma brasileiro e possui uma das maiores biodiversidades do mundo. Tem função reguladora do fluxo dos mananciais hídricos, mantém a fertilidade do solo, controla o equilíbrio climático, e evita deslizamentos de escarpas e encostas de regiões serranas. Desde tempos coloniais vem sofrendo os impactos da atividade exploratória e do crescimento populacional e urbano, que causaram fragmentação de ecossistemas, perda de biodiversidade e deterioração de recursos naturais. Aproximadamente $8,5 \%$ de sua cobertura são áreas preservadas com mais de 100 hectares. A conservação desses fragmentos e a recuperação de áreas degradadas são fundamentais para a manutenção do bioma e da qualidade de vida das populações associadas a ele.

Palavras-chave: Bioma Mata Atlântica. Conservação. Biodiversidade.

Abstract: The Atlantic Rainforest is the third largest brazilian biome and has one of the world's largest biodiversity. It regulates the flow of water sources, keeps soil fertility, controls the climate balance, and avoids the landslide of slopes and hillsides. Since colonial times it has been suffering the impacts of exploitation, population growth and urban expansion, which caused ecosystem fragmentation, biodiversity loss, and deterioration of natural resources. Approximately $8.5 \%$ of its coverage are preserved areas with more than 100 hectares. The conservation of these fragments and the restoration of degraded areas are fundamental to maitain the biome and the life quality of the peoples associated to it.

Keywords: Atlantic Rainforest Biome. Conservation. Biodiversity.

* Professora do Quadro Permanente do Departamento de Engenharia Ambiental e Sanitária da Universidade do Estado de Santa Catarina (UDESC). Doutora em Entomologia pela Universidade Federal do Paraná. Licenciada e Bacharel em Ciêncas Biológicas pela Universidade Federal do Paraná. Pesquisadora na área de levantamento faunístico e biomonitormanto aquático através de macroinvertebrados bentônicos. 


\section{Características da Mata Atlântica}

O Brasil é considerado no planeta o país com a maior diversidade de espécies de plantas e animais. Estimativas recentes mostram que ele deve abrigar em torno de $13 \%$ de todas as espécies do mundo, o que corresponderia a um total de 1,8 milhões de espécies ${ }^{1}$. Destas, aproximadamente 55 mil espécies de plantas e 120 mil espécies de animais já foram descritas ${ }^{2}$.

A Mata Atlântica é o terceiro maior bioma do Brasil e a segunda maior floresta pluvial tropical do continente americano, com uma extensão original de cerca de $1.360 .000 \mathrm{~km}^{2}$. Ela se estende desde o litoral do Nordeste até o Rio Grande do Sul através de 17 estados (AL, BA, CE, ES, PI, GO, MS, MG, RJ, SP, PB, PE, PR, SC, SE, RN, RS) e adentra o interior do continente a partir das regiões Sudeste e Sul até a Argentina e o Paraguai ${ }^{4}{ }^{5}$. É composta por vários ecossistemas florestais e não-florestais, classificados segundo critérios botânicos, fitofisionômicos, geológicos, geográficos, e outros: Floresta Ombrófila Densa, Floresta Ombrófila Mista, Floresta Estacional Semidecidual, Floresta Estacional Decidual, Floresta Ombrófila Aberta, restingas, manguezais, e Campos de Altitude ${ }^{6}$.

O clima tropical úmido predomina, mas o tropical de altitude e subtropical também ocorrem. A temperatura média anual varia de $10^{\circ} \mathrm{C}$ a $20^{\circ} \mathrm{C}$ e a precipitação média anual está acima de $1000 \mathrm{~mm}$, sendo bem distribuídos ao longo do ano. O relevo é composto pelas planícies litorâneas e pelos altiplanos do interior do continente. O solo é bastante variável, desde pouco fecundo em algumas regiões até altamente fértil em outras?.

1 LEWINSOHN, Thomas; PRADO, Paulo. How many species are there in Brazil?, 2005, p. 622.

2 LEWINSOHN, Thomas. Síntese do conhecimento atual da biodiversidade brasileira. 2006, p. 54.

3 MYERS, Norman et al. Biodiversity hotspots for conservation priorities. 2000, p. 854.

4 FUNDAÇÃo SOS MATA ATLÂNTICA/INPE. Atlas dos Remanescentes Florestais da Mata Atlântica no período 2013-2014: Relatório Técnico. 2015, p. 8.

5 TABARELLI, Marcelo et al. Desafios e oportunidades para a conservação da biodiversidade na Mata Atlântica brasileira. 2005, p.133.

6 MMA. Mata atlântica. 2016.

7 PEREIRA, Anísio B. Mata Atlântica: uma abordagem geográfica. 2009, p. 28. 
O bioma é responsável por regular o fluxo dos mananciais hídricos, assegurar a fertilidade do solo, controlar o equilíbrio climático, e proteger escarpas e encostas de serras. A Mata Atlântica apresenta aproximadamente 20 mil espécies de plantas ( $2.7 \%$ do total mundial), sendo 8 mil delas endêmicas; 530 espécies de mamíferos; 1.800 espécies de aves; 680 espécies de répteis; 800 espécies de anfíbios; e 3 mil espécies de peixes ( $2,1 \%$ do total mundial). Há também uma riqueza ainda não mensurada de invertebrados ${ }^{8910}$.

Myers et al. ${ }^{11}$ colocam a Mata Atlântica entre as 25 áreas mundiais de maior interesse em termos de conservação (um hotspot) devido a sua grande diversidade e ao elevado índice de espécies endêmicas, e também por causa do processo acelerado de fragmentação do bioma e da consequente perda de cobertura vegetal ${ }^{12}$.

\section{O estado de conservação da Mata Atlântica}

Atualmente, a Mata Atlântica é considerada provavelmente o bioma mais devastado e ameaçado do planeta, sofrendo um ritmo de mudanças que está entre os mais rápidos observados. A necessidade de ações que visem à conservação é de grande urgência.

O processo de devastação foi iniciado na colonização do Brasil. O bioma, por se estender ao longo da costa do país, sofreu os impactos dos diversos ciclos econômicos pelos quais o Brasil passou durante sua história, particularmente o processo mais recente de urbanização e crescimento das cidades.

Cerca de 120 milhões de brasileiros vivem na porção do território correspondente à área original do Bioma Mata Atlântica, onde estão presentes as maiores cidades do Brasil bem como os principais polos industriais, sendo essas regiões responsáveis por cerca de $80 \%$ do PIB

$8 \quad$ MYERS et al., 2000, p. 853.

9 DRUMMOND, Gláucia, M. Introdução, 2008, p. 40.

10 CAMPANILI, M.; SCHAFFER, W. B. Mata Atlântica: manual de adequação ambiental. 2010, p. 5

11 MYERS et al., 2000, p. 853.

12 GALINDO-LEAL, Carlos; CÂMARA, Ibsen de G. Status do hotspot Mata Atlântica: uma síntese. 2005, p. 3. 
nacional $1^{13}$. A supressão da vegetação, a exploração madeireira, as queimadas, a conversão de campos em pastagens, e as monoculturas são alguns dos impactos que a Mata Atlântica tem sofrido desde o ínicio ${ }^{14}$.

A primeira espécie atingida foi o pau-brasil (Caesalpinia echinata), tendo sido superexplorado e praticamente extinto da costa nacional nos primeiros 100 anos de colonização do território ${ }^{15}{ }^{16}$. Outras espécies de árvores e plantas também foram intensamente exploradas para os mais diversos fins, tanto nas regiões litorâneas quanto no interior do continente, tais como a canela, a peroba, a araucária, e várias espécies de orquídeas e bromélias, estando muitas delas atualmente ameaçadas de extinção ${ }^{1718}$.

Já no século XVI, a vegetação da região litorânea deu lugar aos plantios de cana de açúcar, principalmente nos estados do Nordeste e posteriormente na região Sudeste. O monocultivo baseado no emprego de mão-de-obra escrava estava associado a um modelo de ocupação e de atividades agropastoris que utilizava a floresta de modo indiscriminado para a geração de energia e condução dos engenhos de açúcar, e depois derrubava a floresta para a abertura de novas áreas de cultivo e construção de novos engenhos e moradias ${ }^{1920}$. Segundo Warren Dean ${ }^{21}$, a quantidade de lenha necessária para fornecer energia aos engenhos de açúcar era relativamente grande - algo em torno de quinze quilos de lenha para cada quilo de açúcar produzido. No início, a madeira vinha dos manguezais, depois, passou a ser retirada de florestas virgens.

A partir do século XVIII, os ciclos da mineração e da pecuária causaram grande devastação das florestas no interior do continente. Os chamados sertanejos desbravavam o interior do país em busca de minérios e de áreas para a criação de gado.

13 PINTO, Luiz P.; BRITO, Maria. C. W. Dinâmica da perda da biodiversidade na Mata Atlântica brasileira: uma introdução. 2005, p. 28.

14 DRUMMOND, Gláucia, M. 2008, p. 41.

15 SCHÄFFER, Wigold B.; PROCHNOW, Miriam. Mata Atlântica. 2002, p.14.

16 YOUNG, Carlos E. F. Causas socioeconômicas do desmatamento na Mata Atlântica brasileira. 2005, p. 105.

17 DEAN, Warren. A Ferro e Fogo: A história da devastação da Mata Atlântica brasileira. 1996, p. 210.

18 SCHÄEFFER; PROCHNOW, 2002, p. 14

19 DEAN, 1996, p. 210, p.97.

20 YOUNG, 2005, p. 105.

21 DEAN, 1996, p. 96. 
Com a descoberta de ouro e diamantes na região central do País, uma grande leva de portugueses e escravos africanos passou a habitar a colônia, a qual ganhou uma importância econômica tão grande para Portugal que teve seu status elevado à categoria de vice-reino. Somente no período de 1700 a 1800, 1 milhão de quilos de ouro e 2,4 milhões de quilos de diamantes foram oficialmente registrados pela coroa portuguesa. Além da retirada da mata para a abertura de jazidas, o desflorestamento também ocorreu para a utilização da madeira e da lenha na construção e manutenção das novas vilas e cidades que iam se formando, assim como para a abertura de novos campos de cultivo agrícola e criação de gado, principal fonte de proteínas dos garimpeiros ${ }^{2223}$.

A atividade pecuária que se seguiu à mineração promoveu a queimada de grandes extensões férteis em favor de novas áreas de pastagens, e uma substituição de espécies nativas de gramíneas por espécies exóticas, que se expandiram principalmente nas regiões Sudeste e Sul ${ }^{24}$.

O cultivo do café foi a principal fonte de divisas do Brasil no século XIX e financiou o progresso industrial do país no século $\mathrm{XX}^{26}$. Os principais cultivos ocuparam áreas de Mata Atlântica da região Sudeste e do Norte do Paraná, onde as práticas silviculturais causaram a degradação de uma grande parte do solo 2728 , além de promoverem um desflorestamento maciço para o plantio da monocultura e para a abertura de estradas, ferrovias e expansão das populações.

O extrativismo, bastante praticado na época do Brasil colonial, continuou no século XX com o comércio predatório de peles e plumas de animais e plantas ornamentais tais como orquídeas e bromélias destinadas à Europa. Na metade do século, apenas no estado de São Paulo havia uma produção oficial de cerca de 250 mil peles por ano. A remoção seletiva de madeira de lei nesse período também causou grande impacto nas florestas primárias, que depois eram queimadas, vendidas ou abandonadas ${ }^{30}$. A

\footnotetext{
22 DEAN, 1996, p. 128.

23 YOUNG, 2005, 106.

24 DEAN, 1996, p. 108.

25 YOUNG, 2005, 106.

26 YOUNG, 2005, 106.

27 DEAN, 1996, p. 196.

28 YOUNG, 2005, 106

29 PEREIRA, 2009, P. 44.

30 DEAN, 1996, p. 265, p. 289.
} 
Floresta Ombrófila Mista e a Floresta de Araucárias, no Sul do Brasil, foram alguns dos grandes maciços florestais atingidos pela devastação.

Segundo Carlos Galindo-Leal e Ibsen Câmara ${ }^{31}$, as causas mais recentes da perda de biodiversidade e fragmentação da Mata Atlântica incluem formas intensivas de cultura de soja, a expansão dos reflorestamentos com pínus e eucalipto, a retirada de lenha e o corte ilegal de madeira, a captura ilegal de plantas e animais, a introdução de espécies exóticas, e a construção de represas para a produção de energia elétrica. Ademais, ocorre também o aumento demográfico, a expansão das cidades, portos e estradas, o processo de industrialização, e a poluição decorrente desses fatores.

Segundo Carlos Young ${ }^{32}$, as atividades econômicas agropastoris exerceram e ainda exercem grande pressão sobre a Mata Atlântica devido principalmente ao fato de a maior parte das terras estar concentrada nas mãos de poucos produtores, como latifúndios, desde a época colonial. Esses grandes proprietários geram poucos empregos e criam um mercado de trabalho restrito e instável para os trabalhadores rurais, que se estabelecem, por falta de alternativa, em áreas florestais consideradas de risco ou de grande valor ecológico. Ainda segundo o autor, quando se consideram as regiões Sul, Sudeste e Nordeste juntas, as propriedades com menos de 50 hectares ocupam apenas $20 \%$ da área total, porém correspondem a $76 \%$ do pessoal ocupado na agricultura, enquanto as propriedades com mais de 1.000 hectares ocupam $27 \%$ da área total, empregando apenas 3\% da força de trabalho agrícola.

Além disso, as práticas agrícolas adotadas no país desde a época colonial até muito recentemente seguiam a metodologia de derrubada e queimada de floresta virgem para a abertura de novas áreas de plantio, depois que o solo das que estavam em uso se esgotava sem a aplicação de nenhuma técnica de conservação ou melhoria ${ }^{33}$. Essa metodologia, juntamente com as monoculturas, deteriorou enormemente a Floresta Atlântica primária ao longo dos séculos de vocação agrícola do Brasil.

Segundo Anísio Pereira ${ }^{34}$, o aumento da população e o êxodo rural que ocorreu a partir da segunda metade do século XX levaram a

\footnotetext{
31 GALINDO-LEAL; CÂMARA, 2005, p. 4.

32 YOUNG, 2005, p. 107.

33 DEAN, 1996, p. 283.

34 PEREIRA, 2009, p. 44.
} 
um intenso crescimento das cidades e zonas metropolitanas. Com isso, a construção de rodovias e estradas vicinais, muitas delas cortando trechos de matas de relevo acidentado, causou consideráveis impactos ambientais localizados.

A ocupação desordenada de áreas de risco, tais como encostas com declividade superior a $45^{\circ}$, topos de morro, margens de nascentes, de riachos e de rios, por exemplo, tem ocasionado várias tragédias nas últimas décadas, como os deslizamentos ocorridos na região do Vale do Itajaí em Santa Catarina, em 2008 e os deslizamentos na região serrana do Rio de Janeiro, em 2011, que causaram a morte de mais de mil pessoas e deixaram milhares de desabrigados ${ }^{35} 36$.

Wilgold Schaeffer ${ }^{37}$ argumenta que mesmo os pequenos riachos, quando desprovidos da vegetação marginal (vegetação ciliar) protetora, transbordam durante as chuvas torrenciais. Os morros e encostas ocupados por atividades agropecuárias, obras de infraestrutura ou cidades são os mais suscetíveis a desbarrancamentos e deslizamentos, como foi o caso das catástrofes que se abateram sobre a região de Parati e Angra dos Reis no Rio de Janeiro e o Morro do Baú em Santa Catarina.

Nos dois casos citados, a conjunção de dois eventos foi a causa da tragédia: condições climáticas extremas e a ocupação de áreas de risco com a consequente descaracterização da vegetação nativa. Segundo estudos do Centro de Informações de Recursos Ambientais e Hidrometeorologia de Santa Catarina (EPAGRI-CIRAM) realizados no complexo do Morro do Baú, situado no triângulo formado pelos municípios de Ilhota, Luiz Alves e Gaspar, onde várias propriedades foram soterradas, em cerca de $85 \%$ dos locais atingidos já havia algum tipo de alteração humana (antrópica). Nos 15\% restantes, a cobertura vegetal aparentava ser mais densa e uniforme. A maior parte dos deslizamentos nas áreas antropizadas ocorreu em locais com plantio de pinus e eucalipto $(23,44 \%)$, lavouras de banana $(18,75 \%)$, vegetação rasteira $(17,19 \%)$ e solo exposto $(10,94 \%)$. Nos locais com cobertura vegetal uniforme $(15,53 \%)$ que também sofreram deslizamentos, atividades agrícolas e

\footnotetext{
35 CAMPANILI; SCHEFFER, 2010, p. 69.

36

SCHÄFFER, Wigold B. et al. Áreas de Preservação Permanente e Unidades de Conservação X Áreas de Risco. O que uma coisa tem a ver com a outra? 2011, p. 15.

37

SCHÄFFER, 2011, p. 28.
} 
de reflorestamento, estradas, e faixas desmatadas correspondentes à área por onde passa o gasoduto Brasil-Bolívia também foram observadas ${ }^{38}$.

No caso da Região Serrana do Rio de Janeiro, a situação foi mais devastadora: em 92\% das áreas atingidas pelos deslizamentos havia algum tipo de alteração antrópica e em apenas $8 \%$ se observou a presença de uma vegetação nativa bem conservada. As enchentes e deslizamentos atingiram com muito mais intensidade as margens dos cursos de água e as encostas com alta declividade que eram utilizadas para fins agrícolas ou que continham obras de infraestrutura ou edificações ${ }^{39}$.

Além de protegerem o solo e as encostas, os ecossistemas da Mata Atlântica também fazem a proteção dos recursos hídricos associados ao bioma e que sustentam a maior parte da população brasileira. Atualmente há um consenso a respeito da importância da manutenção das florestas para a conservação desses recursos, pois elas alteram não só o clima regional, aumentando a incidência de chuvas, mas também têm papel ativo na hidrologia do solo, melhorando os processos de infiltração, percolação e armazenamento da água, e diminuindo o escoamento superficial e a ação das águas no processo de erosão do solo ${ }^{40}$.

A realidade dos rios na região da Mata Atlântica é crítica, principalmente para aqueles que atravessam zonas urbanas. Um levantamento feito entre março de 2015 e fevereiro de 2016 pela Fundação SOS Mata Atlântica a fim de examinar a qualidade da água em 183 rios, córregos e lagos de 76 municípios dentro de 11 estados brasileiros, mostrou que $36,3 \%$ dos pontos de coleta analisados apresentam qualidade ruim ou péssima, 59,2\% estão em situação regular, 4,5\% foram avaliados com qualidade de água boa (apenas 13 pontos), e nenhum avaliado como ótimo. A falta de investimentos em saneamento ambiental e em saneamento básico, principalmente no que se refere à coleta e ao tratamento de esgotos domésticos no Brasil, é apontada como a principal causa das precárias condições de qualidade da água dos rios e das grandes bacias hidrográficas do país. A poluição causada por lixo, a retirada da mata ciliar, e a ocupação de áreas de mananciais e abastecimento público

38 VIANNA, Luiz; SOUZA, Juliana. Relatório sobre o levantamento dos deslizamentos ocasionados pelas chuvas de novembro de 2008 no complexo do morro do baú. 2009, p. 5.

39 SCHÄFFER, 2011, p. 83.

40 LINO, Clayton F.; DIAS, Heloísa. Parte I: Conceitos, Princípios e Diretrizes para uma Política de Gestão Integrada de Recursos Hídricos e Florestais. 2003, p. 26. 
também são fatores de degradação ${ }^{41}$. Segundo Fábio Scarano ${ }^{42}$, aproximadamente $29 \%$ das microbacias brasileiras perderam mais de $70 \%$ de sua cobertura vegetal, e $40 \%$ foram cobertas por lagos de hidrelétricas. A maioria dessas microbacias se situa dentro do Bioma Mata Atlântica.

Clayton Lino e Heloísa Dias ${ }^{43}$ destacam os efeitos que a retirada das florestas tem sobre os rios e lagos: aumento da turbidez; diminuição da qualidade da água (eutrofização); assoreamento; enchentes nos períodos de chuva e redução da vazão nas estiagens; mudanças climáticas regionais; mudanças na qualidade do ar; redução da biodiversidade, em decorrência da supressão da flora e fauna locais; e poluição hídrica, em função da substituição da floresta por ocupação humana e atividades agropastoris, urbanas e industriais em geral inadequadas.

Uma das piores consequências dessas alterações ambientais e da fragmentação dos ecossistemas é a diminuição da biodiversidade do Bioma Floresta Atlântica. Acredita-se que os impactos podem causar a perda de cerca de $50 \%$ de todas as espécies ${ }^{44}$, incluindo muitas de interesse econômico, que são utilizadas como fonte de renda e/ou sobrevivência por muitas populações que dependem tradicionalmente desses recursos florestais.

Alexander Vibrans et al. ${ }^{45}$, em um levantamento realizado com comunidades que vivem próximas ou no entorno de áreas florestais observaram que pelo menos 328 espécies da flora nativa de Santa Catarina são utilizadas para os mais diversos fins: madeira, energia, medicina e alimento, e têm grande importância para aquelas populações.

Das 20 mil espécies de plantas presentes no Bioma Mata atlântica, 276 constam da lista oficial de espécies ameaçadas, entre elas o palmito juçara (Euterpe edulis), a araucária (Araucaria angustifolia) e várias orquídeas e bromélias ${ }^{46}$. Muitas dessas espécies, como o palmito e a araucária, são fundamentais na dinâmica de seus respectivos ecossistemas, pois são consideradas espécies-chaves, ou seja, sua extinção poderia

\footnotetext{
41 FUNDAÇÃO SOS MATA ATLÂNTICA. Observando os rios. 2016, p. 21.

42 SCARANO, Fábio R. Mata Atlântica. 2014, p. 103.

43 LINO; DIAS, 2003, p. 27.

44 GUEDES, Maria L.S. et al. Breve incursão sobre a biodiversidade da Mata Atlântica. 2005, p. 40.

45 VIBRANS, Alexander C. et al. Inventário Florístico Florestal de Santa Catarina. 2013, p. 11. 
causar a perda de várias outras espécies que dependem diretamente delas para sobreviver.

Segundo o Livro Vermelho da Fauna Brasileira Ameaçada de Extinção, aproximadamente 380 espécies da Mata Atlântica, ou 60\% do total nacional, estão ameaçadas de extinção e 83 destas são consideradas criticamente em perigo ${ }^{47}$. Quanto aos animais terrestres, 185 vertebrados, dos quais 118 aves, 16 anfíbios, 38 mamíferos e 13 répteis correm risco de extinção. Há também 59 espécies de peixes ameaçados nas bacias do Leste brasileiro, entre a foz do rio São Francisco e o norte de Santa Catarina $^{48}$. Quando uma espécie de animal ou vegetal é extinta de seu ambiente natural, geralmente não há mais possibilidade de retorno ${ }^{49}$, e isto é mais grave para as espécies consideradas endêmicas.

Segundo a Fundação SOS Mata Atlântica ${ }^{50}$, os remanescentes florestais de Mata Atlântica com mais de 100 hectares totalizam 8,5\% da cobertura original. Acrescentando todos os fragmentos de floresta nativa com mais de 3 hectares, o percentual chegaria a 12,5\%.

Um monitoramento feito pela Fundação SOS Mata Atlântica e pelo Instituto Nacional de Pesquisas Espaciais (INPE) nas últimas três décadas (1985 a 2014) mostrou que o bioma sofreu uma supressão de vegetação nativa de 1.887 .596 hectares, sendo o estado do Paraná o mais desmatado (456.514 hectares), seguido por Minas Gerais (383.637 hectares) e Santa Catarina (283.168 hectares) ${ }^{5152}$.

Os maiores remanescentes encontram-se principalmente na região litorânea dos estados de Santa Catarina, Paraná, São Paulo, Rio de Janeiro, Bahia e Região Serrana do Espírito Santo, geralmente associados a unidades de conservação de proteção integral. Na Serra do Mar, apesar de haver uma extensa rede de áreas protegidas, 98,69\% dos remanescentes são menores que 100 hectares, padrão que se repete na região central

\footnotetext{
47 PAGLIA, Adriano; FONSECA, Gustavo; SILVA, José. A Fauna Brasileira Ameaçada de Extinção. 2008, p. 68.

48 CAMPANILI; SCHEFFER, 2010, p. 5.

49 GALINDO-LEAL; CÂMARA, 2005, p. 4.

50 FUNDAÇÃO SOS MATA ATLÂNTICA. MG volta a liderar ranking de desmatamento da Mata Atlântica, 2016a.

51 SOS MATA ATLÂNTICA/INPE, 2015, p. 28.

52 SOS MATA ATLÂNTICA, 2016a.
} 
da Mata Atlântica, entre o sul da Bahia e o Espírito Santo, onde 98,65\% dos fragmentos também possuem área menor ou igual a 100 hectares $^{53}$.

A fragmentação da Mata Atlântica não causa somente a extinção de espécies e a redução da biodiversidade, mas também a eliminação de ecossistemas, de populações, da variabilidade genética, e dos processos ecológicos e evolutivos que mantêm essa diversidade. ${ }^{545} \mathrm{O}$ estoque de material genético de plantas e animais necessários para o manejo de florestas comerciais e de sistemas agrícolas é um exemplo dos benefícios econômicos diretos que são perdidos com a fragmentação ${ }^{56}$.

\section{A Mata Atlântica no Estado de Santa Catarina}

O estado de Santa Catarina está totalmente localizado dentro do Bioma Mata Atlântica. Seus principais ecossistemas são a Floresta Ombrófila Densa (ou Floresta Pluvial Atlântica), a Floresta Ombrófila Mista (ou Floresta com Araucária), a Floresta Estacional Decidual (ou Floresta Subtropical da Bacia do Uruguai), os Campos de Altitude (ou Estepes), e as formações pioneiras de manguezais e restingas na região litorânea ${ }^{57}$.

A Floresta Ombrófila Densa, os manguezais e as restingas cobriam $31 \%$ do território do Estado, ou $30.000 \mathrm{~km}^{2}$, estendendo-se da região litorânea até a encosta leste das Serras do Mar e da Serra Geral ${ }^{58}$.

A Floresta Ombrófila Mista era o maior ecossistema e formava um maciço que ocupava $45 \%$ do território do Estado, ou $42.000 \mathrm{~km}^{2}$, nos planaltos Sul, Central e região Oeste. Os campos de altitude ocorriam intercaladamente nessas regiões e ocupavam 14\% do território do Estado, ou $13.300 \mathrm{~km}^{2} 596061$.

53 PINTO, Luiz P. et al. Mata Atlântica Brasileira. 2006, p. 92.

54 GALINDO-LEAL; CÂMARA, 2005, p. 3. 2013a, p. 95. p. 138.

RANTA, Pertti et al. The fragmented atlantic forest of Brazil. 1998, p. 386.

SCHÄFFER, 2011, p. 21.

SEVEGNANI, Lúcia; SCHROEDER, Edson. A vegetação no contexto brasileiro e catarinense. 2013, p. 77.

SEVEGNANI, Lúcia; LAPS, Rudi R.; SCHROEDER, Edson. A Vertente Atlântica.

SEVEGANI; LAPS; SCHROEDER, 2013a, p. 96.

SEVEGNANI, Lúcia; LAPS, Rudi R.; SCHROEDER, Edson. O Planalto Central. 2013b,

SEVEGNANI, Lúcia; LAPS, Rudi R.; SCHROEDER, Edson. O Oeste. 2013c, p. 175 
A Floresta Estacional Decidual ocorria em 8\% do território do Estado, ou $8.000 \mathrm{Km}^{2}$, percorrendo o vale do Rio Uruguai desde a calha do Rio Pelotas, no planalto Central, até o Oeste, na divisa com a Argentina ${ }^{62} 6364$

Até o início do século XX, o estado de Santa Catarina possuía $95 \%$ de suas florestas preservadas ${ }^{65}$. Recentemente, porém, segundo dados da Fundação SOS Mata Atlântica/INPE ${ }^{66}$, a área de vegetação nativa remanescente é de 2.837.010 hectares no ano-base de 2013/2014, ou $29,6 \%$ do total inicial. Desta, $23,1 \%$ são áreas florestais e $6,5 \%$ são ecossistemas não-florestais (campos de altitude, manguezais e restingas). Entre 2005 e 2014, a taxa de decréscimo da vegetação foi positiva e o Estado perdeu 32.010 hectares. Isso significa que a cada ano um pouco do Bioma Mata Atlântica é removido em favor da agropecuária, da silvicultura, da instalação de barragens, ou da expansão industrial e urbana.

Um levantamento florístico-florestal realizado entre 2007 e 2011 nos ecossistemas do Estado mostrou que restam aproximadamente $40 \%$ de Floresta Ombrófila Densa, 24\% de Floresta Ombrófila Mista e 16\% de Floresta Estacional Decidual ${ }^{67}$.

Segundo Alexander Vibrans et al. ${ }^{68}, 2.341$ espécies de plantas vasculares foram contabilizadas, um número $20 \%$ menor do que o total catalogado em outro levantamento realizado entre 1950 e 1970. Entre as espécies não encontradas estão aquelas consideradas naturalmente raras, as que ocorrem em pequena quantidade, e as que estão presentes em poucos locais ou em locais muito restritos. Além da redução do número de espécies coletadas, as populações também foram reduzidas para aproximadamente $30 \%$ no ambiente natural.

A maior parte dos fragmentos que compõem a Floresta Ombrófila Densa no estado de Santa Catarina é constituída de floresta perturbada, em diferentes graus de regeneração e com simplificação da estrutura e do conjunto de espécies. Esses fragmentos continuam sofrendo corte seletivo

\footnotetext{
62 VIBRANS et al., 2013, p. 26.

63 SEVEGANI; LAPS; SCHROEDER, 2013b, p. 138.

64 SEVEGANI; LAPS; SCHROEDER, 2013c, p. 175.

65 SCHÄEFFER; PROCHNOW, 2002, p. 18.

66 FUNDAÇÃO SOS MATAATLÂNTICA/INPE, 2015, p. 46.

67 VIBRANS et al., 2013, p. 4.

68 VIBRANS et al., 2013, p. 5.
} 
de espécies, extração ilegal de palmito, invasão de espécies exóticas, e cedendo espaço para a abertura de estradas e para a criação de gado ${ }^{69} 70$. A mesma tendência é observada nos ecossistemas litorâneos (manguezais e restingas) dos quais restaram aproximadamente $28 \%$ do total inicial ${ }^{71}$.

Aproximadamente $82 \%$ dos fragmentos de Floresta Ombrófila Mista são menores que 50 hectares e se encontram isolados pela agricultura, pelos povoamentos, pelas plantações de pínus e eucalipto, e pelas pastagens, o que demonstra que as alterações de seu tamanho e de sua composição florística e faunística decorrem de ações antrópicas diretas ou indiretas com variadas intensidades ${ }^{72} 73$.

A Floresta Estacional Decidual é a mais reduzida. Seus fragmentos são isolados por extensas áreas agrícolas ou pastoris e continuam a sofrer ações degradadoras diversas, exploração seletiva e corte raso ${ }^{7475}$.

Aproximadamente $90 \%$ dos remanescentes florestais de Santa Catarina apresentam área menor que 50 hectares $^{76}$. A redução e o empobrecimento dessas florestas e a fragilização de sua estrutura têm afetado significativamente sua função de proteção do solo e dos mananciais e sua utilidade como reservatório de carbono.

\section{Perspectivas futuras para a Mata Atlântica}

Segundo Luiz Pinto et al. ${ }^{77}$, a forte pressão antrópica sobre os ecossistemas do Bioma Mata Atlântica resulta de um conhecimento insuficiente a respeito de seu funcionamento e da complexidade das relações sociais e econômicas que o afetam. Apesar dos muitos instrumentos legais elaborados nas últimas décadas para proteger a Mata Atlântica, atividades ilícitas tais como o corte de madeira, a captura de fauna e flora e os assentamentos clandestinos ainda são comuns. Essas ações concorrem

\footnotetext{
69 MEDEIROS, João de D. Mata Atlântica em Santa Catarina. 2002, p. 104.

70 VIBRANS et al., 2013, p. 29.

71 SEVEGANI; LAPS; SCHROEDER, 2013a, p. 95.

72 MEDEIROS, 2002, p. 103.

73 VIBRANS et al., 2013, p. 22.

74 MEDEIROS, 2002, p. 103.

75 VIBRANS et al., 2013, p. 16.

76 VIBRANS et al., 2013, p. 8.

77 PINTO et al., 2006, p. 91.
} 
continuamente para a deterioração das florestas remanescentes ${ }^{78}$, mas com frequência são explicadas pela falta de alternativa ou de conhecimento.

Da mesma forma, políticos, industriais e ruralistas ainda trabalham com um modelo de desenvolvimento econômico predatório, que visa o lucro em detrimento da qualidade ambiental. A tragédia da cidade mineira de Mariana em novembro de 2015, que afetou mais de $500 \mathrm{~km}$ do Rio Doce, especialmente em seu trecho que atravessa uma parte de Mata Atlântica da região, é um exemplo dessa mentalidade.

Atualmente, os fragmentos mais preservados da Mata Atlântica encontram-se no interior das Unidades de Conservação (UCs). Em Santa Catarina, cerca de $2 \%$ de seu território está protegido dentro de parques e reservas nacionais, estaduais, municipais e particulares, localizadas principalmente em propriedades privadas. Essa área é insuficiente para a conservação de toda a biodiversidade do Estado $^{79}$. Novas Unidades de Conservação dos remanescentes de Mata Atlântica devem ser criadas não só em Santa Catarina, mas em todo o país. Para tanto, é necessário conduzir estudos que avaliem sua importância em termos de biodiversidade, taxa de endemismo e preservação de recursos.

A restauração da vegetação nativa de áreas já degradadas tais como topos de morro, regiões de mananciais e matas ciliares proporcionará segurança e outros benefícios às populações silvestres e humanas que habitam essas áreas.

A participação das comunidades pode ser incentivada através de projetos de manejo florestal sustentável que combinem adequadamente as necessidades financeiras com a preservação da biodiversidade e dos recursos naturais. É também importante trabalhar a sensibilização ambiental de todos os que vivem na região da Mata Atlântica, a fim de promover uma diminuição do consumo de recursos naturais e da geração de resíduos poluentes.

O setor governamental deve fazer cumprir as leis de proteção ambiental, bem como promover uma fiscalização efetiva dos setores que geram resíduos e dos que podem causar impactos sobre os remanescentes florestais. Deve também melhorar o saneamento básico das cidades, principalmente seus sistemas de tratamento de esgoto e destinação de lixo.

78 GALINDO-LEAL; CÂMARA, 2005, p. 10.

79 SCHÄEFFER; PROCHNOW, 2002, p. 18. 
Salientemos a contribuição das instituições de pesquisas, fundações, organizações não-governamentais e tantas outras que, além de trabalhar conjuntamente em prol da construção de um conhecimento consistente a respeito da dinâmica dos vários ecossistemas que compõem o bioma Mata Atlântica, monitoram seus recursos e sua biodiversidade e desenvolvem ações de manejo, sustentabilidade e educação que não só promovem a preservação de áreas críticas, mas também a melhoria da qualidade de vida das populações envolvidas.

O futuro do Bioma Mata Atlântica e dos demais biomas brasileiros depende da ação conjunta e bem dirigida da sociedade na busca de soluções coerentes para a grave crise ambiental em que o país se encontra atualmente.

\section{Referências}

CAMPANILI, M.; SCHAFFER, W. B. Mata Atlântica: manual de adequação ambiental. Brasília: MMA/SBF, 2010.

DEAN, Warren. A Ferro e Fogo: A história da devastação da Mata Atlântica brasileira. São Paulo: Companhia das Letras, 1996.

DRUMMOND, Gláucia M. Introdução. In: MACHADO, Angelo B. M.; ; Paglia, Adriano P. (orgs). Livro vermelho da fauna brasileira ameaçada de extinção. 1. ed., Brasília: MMA; Belo Horizonte: Fundação Biodiversitas, 2008. p. 39-42.

FUNDAÇÃO SOS Mata Atlântica. $M G$ volta a liderar ranking de desmatamento da Mata Atlântica: Histórico do desmatamento. São Paulo: Fundação SOS Mata Atlântica. 2016a. Disponível em: < https://www. sosma.org.br/105066/mg-volta-liderar-ranking-de-desmatamento-da-mata-atlantica/>. Acesso em: 27 nov. 2016.

FUNDAÇÃO SOS Mata Atlântica. Observando os rios: O retrato da qualidade da água em rios das regiões sul, sudeste e nordeste do Bioma Mata Atlântica e Distrito Federal. São Paulo: Fundação SOS Mata Atlântica. 2016b. Disponível em: <https://www.sosma.org.br/wp-content/ uploads/2016/03/relatorio_rios_2016.pdf >. Acesso em: 22 nov. 2016.

FUNDAÇÃO SOS MATAATLÂNTICA/INPE. Atlas dos Remanescentes Florestais da Mata Atlântica no período 2013-2014: Relatório Técnico. São Paulo: Fundação SOS Mata Atlântica, 2015. Disponível em: <http:// 
mapas.sosma.org.br/site_media/download/atlas_2013-2014_relatorio_tecnico_2015.pdf>. Acesso em: 23 nov. 2016.

GALINDO-LEAL, Carlos; CÂMARA, Ibsen de G. Status do hotspot Mata Atlântica: uma síntese. In: . Mata atlântica: biodiversidade, ameaças e perspectivas. Belo Horizonte: Fundação SOS Mata Atlântica, 2005. p. 3-11.

GUEDES, Maria L.S. Breve incursão sobre a biodiversidade da Mata Atlântica. In: FRANKE, Roberto C. et al. (Org.). Mata Atlântica e Biodiversidade. Salvador: Edufba, 2005. p. 39-92.

LEWINSOHN, Thomas; PRADO, Paulo I. How Many Species Are There in Brazil? Conservation Biology, Washington, v.19, p. 619-624, 2005.

LEWINSOHN, Thomas. Síntese do conhecimento atual da biodiversidade brasileira. In: (Org). Avaliação do estado do conhecimento da biodiversidade brasileira. Brasília: Ministério do Meio Ambiente, 2006, p. 21-109.

LINO, Clayton F.; DIAS, Heloísa. Parte I: Conceitos, Princípios e Diretrizes para uma Política de Gestão Integrada de Recursos Hídricos e Florestais. In: (Org.). Águas e florestas da mata atlântica: por uma gestão integrada. São Paulo: Conselho Nacional da Reserva da Biosfera da Mata Atlântica, 2003. p. 13-67.

MEDEIROS, João de D. Mata Atlânticaem Santa Catarina: Situação atual e perspectivas futuras. In: SCHÄFFER, Wigold B.; PROCHNOW, Miriam (Org.). Mata Atlântica e você: como preservar, recuperar e se beneficiar da mais ameaçada floresta brasileira. Brasília: APREMAVI, 2002.

MMA - Ministério do Meio Ambiente. Mata Atlântica. Brasília, 2016. Disponível em: <http://www.mma.gov.br/biomas/mata-atlantica>. Acesso em: 24 nov. 2016.

MYERS, Norman et al. Biodiversity hotspots for conservation priorities. Nature, London, v. 403, p. 853-858, 2000.

PAGLIA, Adriano P.; FONSECA, Gustavo A. B.; SILVA, José M. C. A Fauna Brasileira Ameaçada de Extinção: síntese taxonômica e geográfica. In: MACHADO, Angelo B. M.; DRUMMOND, Gláucia M; (orgs). Livro vermelho da fauna brasileira ameaçada de extinção. Brasília: MMA; Belo Horizonte: Fundação Biodiversitas, 2008, p. 63-70. 
PEREIRA, Anísio B. Mata Atlântica: uma abordagem geográfica. $\mathrm{Nu}$ cleus, Ituverava, v. 6, p. 27-53, abr. 2009.

PINTO, Luiz P. et al. Mata Atlântica Brasileira: os Desafios para Conservação da Biodiversidade de um Hotspot Mundial. In: ROCHA, C.F.D. et al. (orgs.). Biologia da Conservação: essências. São Carlos, RiMa. p. 91-118.

PINTO, Luiz P.; BRITO, Maria. C. W. Dinâmica da perda da biodiversidade na Mata Atlântica brasileira: uma introdução. In: GALINDO-LEAL, Carlos; CÂMARA, Ibsen de G. Mata atlântica: biodiversidade, ameaças e perspectivas. Belo Horizonte: Fundação SOS Mata Atlântica, 2005, p. 27-30.

RANTA, Pertti et al. The fragmented atlantic forest of Brazil: size, shape and distribution of forest fragments. Biodiversity Conservation, Amsterdã, v.7, p. 385-403. 1998.

SCARANO, Fábio R. Mata Atlântica: uma história do futuro. 1. ed. Rio de Janeiro: Edições de Janeiro, 2014.

SCHÄFFER, Wigold B.; PROCHNOW, Miriam. Mata Atlântica. In: (Org.) Mata Atlântica e você: como preservar, recuperar e se beneficiar da mais ameaçada floresta brasileira. Brasília: APREMAVI, 2002.

SCHÄFFER, Wigold B. et al. Áreas de Preservação Permanente e Unidades de Conservação X Áreas de Risco. O que uma coisa tem a ver com a outra? Relatório de Inspeção da área atingida pela tragédia das chuvas na Região Serrana do Rio de Janeiro. Brasília: MMA, 2011.

SEVEGNANI, Lúcia; SCHROEDER, Edson. A vegetação no contexto brasileiro e catarinense: uma síntese. In: (org.). Biodiversidade catarinense: características, potencialidades, ameaças. Blumenau: Edifurb, 2013, p. 71-92.

SEVEGNANI, Lúcia; LAPS, Rudi R.; SCHROEDER, Edson. A Vertente Atlântica. In: SEVEGNANI, Lúcia; SCHROEDER, Edson (org.). Biodiversidade catarinense: características, potencialidades, ameaças. Blumenau: Edifurb, 2013a. p. 93-133.

SEVEGNANI, Lúcia; LAPS, Rudi R.; SCHROEDER, Edson. O Planalto Central. In: SEVEGNANI, Lúcia; SCHROEDER, Edson (org.). Biodiversidade catarinense: características, potencialidades, ameaças. Blumenau: Edifurb, 2013b, p. 93-171. 
SEVEGNANI, Lúcia; LAPS, Rudi R.; SCHROEDER, Edson. O Oeste. In: SEVEGNANI, Lúcia; SCHROEDER, Edson (org.). Biodiversidade catarinense: características, potencialidades, ameaças. Blumenau: Edifurb, 2013 a. p. 173-195.

TABARELLI, Marcelo et al. Desafios e oportunidades para a conservação da biodiversidade na Mata Atlântica brasileira. Megadiversidade, Belo Horizonte, v. 1, p. 132-138, 2005.

VIANNA, Luiz F.; SOUZA, Juliana, M. Relatório sobre o levantamento dos deslizamentos ocasionados pelas chuvas de novembro de 2008 no complexo do morro do baú municípios de Ilhota, Gaspar e Luiz Alves. EPAGRI/CIRAM. Florianópolis, 2009.

VIBRANS, Alexander C. et al. Inventário Florístico Florestal de Santa Catarina: resultados resumidos. Blumenau: Universidade Regional de Blumenau, 2013.

YOUNG, Carlos E. F. Causas socioeconômicas do desmatamento na Mata Atlântica brasileira. In: GALINDO-LEAL, Carlos; CÂMARA, Ibsen de G. Mata atlântica: biodiversidade, ameaças e perspectivas. Belo Horizonte: Fundação SOS Mata Atlântica, 2005. p. 103-118.

E-mail da autora: josiane.cardoso@udesc.br 